\title{
Postnatal hypothermia and cold stress among newborn infants in Nepal monitored by continuous ambulatory recording
}

\author{
M Ellis, N Manandhar, U Shakya, D S Manandhar, A Fawdry, A M de L Costello
}

\begin{abstract}
Aims-To describe the pattern of hypothermia and cold stress after delivery among a normal neonatal population in Nepal; to provide practical advice for improving thermal care in a resource limited maternity hospital.
\end{abstract}

Methods-The principal government funded maternity hospital in Kathmandu, Nepal, with an annual delivery rate of 15000 (constituting $40 \%$ of all Kathmandu Valley deliveries), severe resource limitations (annual budget $£ 250000$ ), and a cold winter climate provided the setting. Thirty five healthy term neonates not requiring special care were enrolled for study within 90 minutes of birth. Continuous ambulatory temperature monitoring, using microthermistor skin probes for forehead and axilla, a flexible rectal probe, and a black ball probe placed next to the infant for ambient temperature, was carried out. All probes were connected to a compact battery powered Squirrel Memory Logger, giving a temperature reading to $0.2^{\circ} \mathrm{C}$ at five minute intervals for 24 hours. Severity and duration of hypothermia, using cutoff values of core temperature less than $36^{\circ} \mathrm{C}, 34^{\circ} \mathrm{C}$, and $32^{\circ} \mathrm{C}$; and cold stress, using cutoff values of skin-core (forehead-axilla) temperature difference greater than $3^{\circ} \mathrm{C}$ and $4^{\circ} \mathrm{C}$ were the main outcome measures.

Results-Twenty four hour mean ambient temperatures were generally lower than the WHO recommended level of $25^{\circ} \mathrm{C}$ (median $22.3^{\circ} \mathrm{C}$, range $15.1-27.5^{\circ} \mathrm{C}$ ). Postnatal hypothermia was prolonged, with axillary core temperatures only reaching $36^{\circ} \mathrm{C}$ after a mean of 6.4 hours (range 0 - 21.1; SD 4.6). There was persistent and increasing cold stress over the first 24 hours with the core-skin (axillaryforehead) temperature gap exceeding $3^{\circ} \mathrm{C}$ for more than half of the first 24 hours. Conclusions-Continuous ambulatory recording identifies weak links in the "warm chain" for neonates. The severity and duration of thermal problems was greater than expected even in a hospital setting where some of the WHO recommendations had already been implemented.

(Arch Dis Child 1996;75:F42-F45)

Keywords: postnatal hypothermia, continuous ambulatory recording, skin temperature, resources.
Neonatal hypothermia is a common problem in many developing countries including Nepal. ${ }^{1-3}$ It is associated with an increased risk of mortality in a hospital setting in a developing country, ${ }^{4}$ and also with an increased risk of morbidity such as hypoglycaemia, apnoea, and acidosis. Thermal control of neonates is currently being incorporated into the World Health Organisation (WHO) Safer Motherhood Programme, ${ }^{5}$ and is an important element of the Baby Friendly Hospital initiative led by the United Nations Children's Fund (UNICEF).

Previous studies of neonatal temperature control and the epidemiology of hypothermia in developing countries have relied on discrete measurements taken from single sites over wide time intervals. The act of measurement may disturb the behavioural and thermal status of the infant, and single measurements make no estimate of the duration of hypothermia experienced by infants.

In this paper we describe continuous ambulatory multiple site temperature monitoring over the first 24 hours of life, in a series of term babies undergoing routine postnatal care in a hospital setting in Nepal. The aims of the study were to evaluate the feasibility of ambulatory monitoring of neonatal temperature in such a setting, and to describe the pattern of hypothermia after delivery and cold stress among the normal neonatal population.

\section{Methods}

The study was conducted at Prasuti Griha Maternity Hospital, Kathmandu, between December 1993 and April 1994. This government funded hospital has 220 beds and provides for more than 14000 deliveries a year, with extremely limited resources (estimated annual budget $£ 250000$ ). After delivery newborn infants are usually dried and wrapped below a radiant heater. Once a postnatal bed is found (which can take up to 6 hours) mother and infant share a single bed where they lie side by side, the infant clothed in cotton wraps and wool shawls. Intimate skin to skin contact between mother and infant is not practised except during breastfeeding. The hospital has no central heating system and poor thermal insulation.

CONTINUOUS TEMPERATURE RECORDING Forty seven neonates were recruited for continuous ambulatory, multiple site, temperature recording after their mothers had given 
informed consent. Investigators visited the labour room, usually in the morning, and enrolled the first available term infant. Only those born with an uncomplicated, normal delivery who had no signs of illness or congenital abnormality, and in whom recording could start within 90 minutes of birth were enrolled.

Two microthermistor skin probes were attached with standard hospital tape to the baby's forehead and axilla, respectively. A third $5 \mathrm{~mm}$ diameter linear flexible rectal probe was inserted $3 \mathrm{~cm}$ into the rectum and a fourth black ball ambient probe was placed next to the infant. All four probes carry $2 \mathrm{~K}$ Fenwall Thermistors, giving a temperature reading to $0.2^{\circ} \mathrm{C}$ between 0 and $50^{\circ} \mathrm{C}$. All probes were connected to a compact battery powered Squirrel Memory Logger (Model No MQ 32 4U; Grant Instruments, Cambridge, UK) which was programmed to record simultaneous thermistor readings from all four sites at 5 minute intervals for 24 hours.

Because an earlier pilot study found the rectal probe prone to slippage, axillary readings were selected as our gold standard of core temperature. In two cases the software malfunctioned, in two cases data were lost during downloading, and in a further eight cases there was intermittent poor contact of the axillary thermistor. Thus continuous core and ambient temperature readings were available for 35 babies. Of these, the forehead skin probe had significant loss of contact in 15 babies for parts of the 24 hour period. Therefore, complete 24 hour records of core-skin temperature differences were available for 20 babies. In 19 of the 35 babies significant rectal probe contact loss occurred, confirming our pilot study findings.

\section{HYPOTHERMIA AND COLD STRESS}

The World Health Organisation classifies a core temperature of $32-36^{\circ} \mathrm{C}$ as moderate hypothermia, and below $32^{\circ} \mathrm{C}$ as severe hypothermia. ${ }^{5}$ Data on the duration of hypoth-

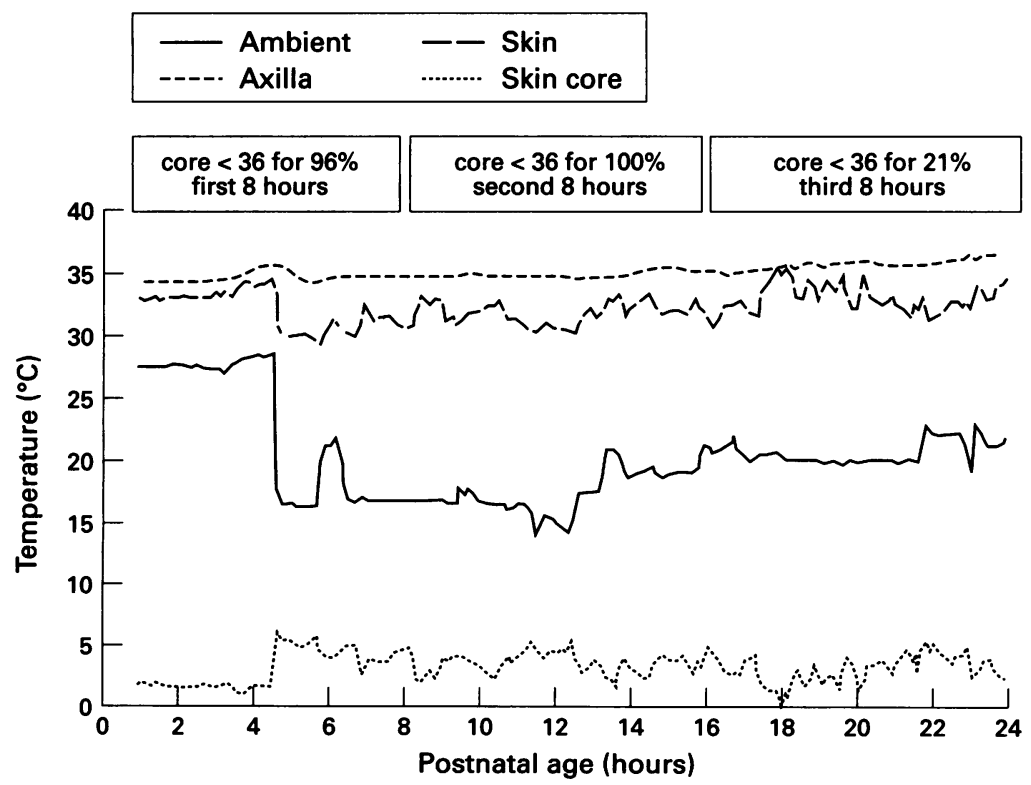

Figure 1 Representative 24 hour temperature record showing axillary (core), forehead (skin), and ambient temperatures, and core-skin temperature difference: case 20, female, $2.42 \mathrm{~kg}$ birthweight.
Table 2 Ambient temperatures by month of year

\begin{tabular}{lll}
\hline & $\begin{array}{l}\text { No of ambient } \\
\text { temperature values } \\
\text { recorded } \\
\text { (No of infants studied) }\end{array}$ & $\begin{array}{l}\text { Ambient temperature } \\
\text { (mean (SD) and range) }\end{array}$ \\
\hline Donth & $891(3)$ & $19.7(4.3) 15.1-23.6$ \\
January & $2947(10)$ & $20.0(2.6) 15.8-24.2$ \\
February & $1766(6)$ & $22.0(3.0) 18.0-27.1$ \\
March & $2619(9)$ & $23.0(2.1) 20.6-27.5$ \\
April & $2039(7)$ & $24.6(1.3) 23.3-27.2$ \\
\hline
\end{tabular}

ermia are presented using cutoffs of $36^{\circ} \mathrm{C}$, $34^{\circ} \mathrm{C}$, and $32^{\circ} \mathrm{C}$.

Cold stress may occur below the lower critical temperature - that is, the ambient temperature below which the rate of metabolic heat production of a resting thermoregulating subject increases by shivering and/or nonshivering thermogenic processes to maintain thermal balance. ${ }^{6}$ Early studies of the thermoneutral zone indicated that cold stress begins when mean skin temperature is lowered to $35-36^{\circ} \mathrm{C}$. The Servo control of modern incubators is based on an abdominal temperature of about $36.5^{\circ} \mathrm{C}$ with a relative humidity of $50 \%$.

To estimate the normal core-skin temperature difference (using axillary and forehead readings), four healthy term infants staying on the special care baby unit (usually after caesarean section) and nursed in open cots in ambient temperatures above $25^{\circ} \mathrm{C}$ were studied. Eighteen periods of 120 minutes of continuous recording were analysed. The mean core-skin temperature difference was $2.9^{\circ} \mathrm{C}(2.6-3.4$, $95 \%$ confidence interval). Although these infants were warm, even they were not in strictly thermoneutral conditions. From this evidence cutoff temperature difference values of $>3^{\circ} \mathrm{C}$ and $>4^{\circ} \mathrm{C}$ were chosen to present data on the duration of cold stress.

Data were downloaded from the data logger to a portable IBM computer, initially analysed using Squirrelwise Software, and transferred for further analysis using Statview 4.02. Duration of hypothermia or cold stress were analysed as the mean percentage of time spent below a cutoff value, with the range expressed as 10 th and 90 th centile values.

\section{Results}

Clinical details of the 35 infants studied are shown in table 1 . The sample was representative of newborn infants in Nepal in terms of birthweight, but the study infants were usually placed at the breast within the first 6 hours, an uncommon practice in much of southern Asia. This reflects greater encouragement of mothers to breastfeed by midwives in this maternity hospital. Early breastfeeding should reduce the risk of hypothermia. ${ }^{7}$ Most infants spent much of the first 24 hours of life in temperatures well below the WHO recommended level of $25^{\circ} \mathrm{C}$. Table 2 shows the ambient temperatures experienced by the infants over the study period. The maximum temperatures were short-lived and occurred in the period immediately after birth as the infants lay beneath radiant heaters.

When the 24 hour record for individual infants was studied, a characteristic pattern was seen in our hospital (fig 1). For this infant 
Table 1 Clinical details of study cases $(n=35)$

\begin{tabular}{ll}
\hline Maternal age, years (mean, range) & $21.1(15-33)$ \\
Infant sex (male:female) & $13: 22$ \\
Birth weight, kg (mean, range) & $2.7(2.2-3.3)$ \\
Number of breast feeds taken by infant & \\
$\quad$ in first 24 hours (mean, range) & $7(2-12)$ \\
Time to first feed (hours) & \\
$0-5$ & 2 \\
$6-11$ & 5 \\
$12-17$ & 8 \\
18-24 & 11 \\
Number of wraps around infant & \\
(mean, range) cotton=1, wool $=2$ & $7(2-14)$ \\
\hline
\end{tabular}

there was a period of immediate postnatal hypothermia lasting several hours. While under the labour room radiant heater cold stress was kept to a minimum with a core-skin gap of just over $1^{\circ} \mathrm{C}$. As the neonate was taken to the cold postnatal wards cold stress increased, evidenced by the rapid development of a core-skin gap of over $5^{\circ} \mathrm{C}$. Cold stress persisted throughout the whole of the remaining 24 hour period.

For all infants studied it took, on average, 6.4 hours (range 0-21.1; SD 4.6) from birth for the infant's core temperature to reach $36^{\circ} \mathrm{C}$. Mean core temperature (MCT) for the group as a whole during the first 8 hours of life was $35.1^{\circ} \mathrm{C}$ (range $32.2-36.6$; SD 1.0), but rose with age in the second 8 hours of life; MCT was $36.1^{\circ} \mathrm{C}$ (range $32.7-37.1$; SD 0.8 ) and $36.4^{\circ} \mathrm{C}$ (range $33.2-37.2$; SD 0.8 ) in the third 8 hours. In three of the 35 infants axillary recordings below $32^{\circ} \mathrm{C}$ were registered.

Table 3 presents data on the duration of different levels of severity of hypothermia (low axillary temperature) and cold stress (axillaryforehead temperature difference) for each of the first three 8 hour periods after birth.

The mean percentage of time spent at a core temperature below $36^{\circ} \mathrm{C}$ fell from $72 \%$ during the first 8 hours to $31 \%$ and $15 \%$ in the second and third 8 hour periods. In contrast, axillaryforehead temperature differences tended to widen over the 24 hour period. In 20 infants for whom complete data sets were available the temperature gap exceeded $3^{\circ} \mathrm{C}$ for $46 \%, 50 \%$, and $60 \%$, respectively, of the time in the first three 8 hour periods after birth. The same infants spent $14-18 \%$ of the time with a core-skin difference above $4^{\circ} \mathrm{C}$.

\section{Discussion}

This study has shown that continuous ambulatory 24 hour temperature monitoring with compact battery powered data logging equipment is potentially useful as a research and audit method in the routine postnatal environment of a maternity hospital in a developing country. Continuous ambulatory monitoring has shed light on weak links in early thermal care. The 24 hour records graphically illustrate when the "warm chain" breaks down. This technique will be of use to any agency or institution concerned with the evaluation of early infant care in developing country settings-for example, under the Baby Friendly Hospital initiative.

Continuous rectal temperature monitoring was notably less successful than axillary monitoring as a measure of core temperature, but previous studies have shown that axillary temperatures are reliable estimates of core temperature in neonates. ${ }^{8}$ We have confirmed these findings by showing no significant difference between rectal and axillary temperature values on the data logger if the rectal probe is inserted at least $5 \mathrm{~cm}$. At $3 \mathrm{~cm}$ or less the rectal temperature value was up to $0.5^{\circ} \mathrm{C}$ lower than the axillary value.

Previous studies using single measures of temperature have shown a high incidence of neonatal hypothermia in similar settings, but our research method yields important information on the underlying patterns of hypothermia in the neonatal period. We found most infants over the winter months were moderately hypothermic according to WHO criteria $\left(32-36^{\circ} \mathrm{C}\right)^{5}$ for much of the first 8 hours of life. Yet all of the babies studied had recovered to $36^{\circ} \mathrm{C}$ before 24 hours had elapsed. This represents an improvement since the observational study performed by Johanson et $a l^{3}$ at the same hospital five years ago when $49 \%$ of babies were still moderately hypothermic at 24 hours of age in the cold season. Since then, training of staff has emphasised early drying and wrapping, and early breastfeeding, as essential elements of the "warm chain." Our study suggests the intervention has been both effective and sustained if we take the achievement of a core temperature of $36^{\circ} \mathrm{C}$ by 24 hours as the desired endpoint.

Examination of the subjects' 24 hour records, however, shows a weak link in our "warm chain." In the example shown (fig 1) early drying and wrapping in conjunction with temporary placement beneath an overhead radiant heater did indeed minimise early temperature loss. But as the infant was transferred to the postnatal ward a substantial increase in core-skin temperature gap occurred with an associated drop in core temperature. This represented an avoidable additional cold stress on the infant and prolonged the time taken for core temperature to recover to $36^{\circ} \mathrm{C}$. In the light of these findings the hospital plans to test whether infants should be in skin to skin contact within the draught protection of mother's gown ("kangarooed") during the vulnerable period of transfer to the ward.

Once core temperature had recovered to $36^{\circ} \mathrm{C}$, most infants showed a continuing wide core-skin difference, that persisted throughout the first 24 hours. We believe this indicates continuing cold stress. Other possible explanations for core-skin differences include local vasoconstriction on the forehead when exposed to cold air, or a contraction in circulating blood volume, perhaps as a result of early cord clamping. One advantage of selecting the forehead as a site for skin temperature measurement is that vasomotor nerves exert only a slight effect on the forehead, and there is practically no vasoconstriction in response to cold stress. ${ }^{9}$ Local vasoconstriction therefore seems to be an unlikely explanation. The contribution of changes in circulating blood volume cannot be ruled out, especially as the usual practice in the hospital is to clamp the cord early. Certainly inspection of all individual 24 hour 
Table 3 Severity and duration of hypothermia and cold stress experienced by newborn infants in the first 24 hours

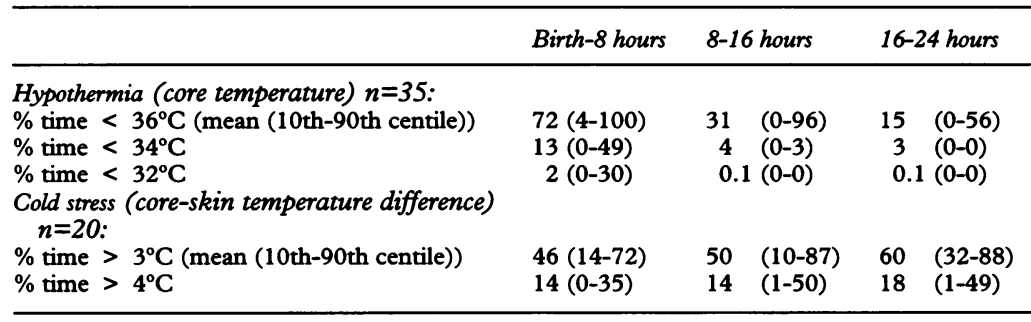

records does not show a consistent pattern of a late fall in skin temperature, which might be expected if circulatory changes are the primary cause. In many cases the core-skin temperature difference closely tracks the ambient temperature, suggesting this is likely to be more important than circulatory factors. Preliminary analysis of data collected on other neonates during the summer months also shows significant differences in core-skin temperature between infants nursed above and below $25^{\circ} \mathrm{C}$.

Does cold stress matter? Non-shivering thermogenesis is triggered when the skin temperature falls to $35-36^{\circ} \mathrm{C}$ even when core temperature remains normal. ${ }^{10}$ There is also evidence that infants exposed to a slightly sub-thermoneutral environment compared with those nursed within the thermoneutral zone have a higher mortality rate, ${ }^{411}$ slower growth on a fixed calorie intake, ${ }^{12}$ and a lower consumption of colostrum. ${ }^{13}$ Ingestion of colostrum is in turn associated with a considerable increase in metabolic rate which contributes to the maintenance of body temperature. Conversely, cold stress may have some positive effects, acting as a ventilatory stimulus and as an inducer of mechanisms favouring cold resistance. ${ }^{14}$ Further research is needed to evaluate the significance of high levels of cold stress among newborn infants in a developing country setting like Nepal, and its effects on metabolic adaptation, morbidity, and mortality.

Singh et al, in India, noted that nearly $20 \%$ of term infants had a core-skin difference of greater than $2^{\circ} \mathrm{C}$ at ambient temperatures of $26-28^{\circ} \mathrm{C}$. ${ }^{15}$ They demonstrated the sensitivity of skin temperature assessment by experienced observers using touch alone to detect both early cold stress and hypothermia. Our findings suggest that cold stress is much more common at lower ambient temperatures, and staff training in "touch assessment" may be important in identifying vulnerable infants.

We are grateful to the British Government Overseas Development Administration and to the Wellcome Trust for financial assistance with this study.

1 Ji XC, Zhu CY, Pang RY. Epidemiological study on hypothermia in newborns. Chin Med $\mathcal{F} 1993 ; 106: 428-32$.

2 Karan S, Rao MN, Urmila S, Rajaji S. The incidence, clinical profile, morbidity and mortality of hypothermia in the newborn. Indian Pediatr 1975; 12:1205-10.

3 Johanson RB, Spencer SA, Rolfe P, Jones P, Malla DS. Effect of post-delivery care on neonatal body temperature. Acta Paediatr 1992; 81:859-63.

4 Tafari N. Hypothermia in the tropics: epidemiologic aspects. In: Sterky $\mathrm{G}$, Tunell $\mathrm{R}$, Tafari $\mathrm{N}$, eds. Fudging the appropriateness of technology. Stockholm: SAREC, 1985 45-50.

5 WHO. Thermal control of the newborn: a practical guide. (Maternal Health and Safe Motherhood Programme) Geneva: WHO, 1993.

6 Heim T. Homeothermy and its metabolic cost. In: Davis J, Dobbing J, eds. Scientific foundations of paediatrics. London: Dobbing J, eds. Scientific foundations of paediat

7 Van den Bosch CA, Bullough CHW. The effect of early suckling on term neonates' core body temperature. Annals of Tropical Paediatrics 1990; 10:347-53.

8 Schiffman RF. Temperature monitoring in the neonate. A comparison of axillary and rectal temperatures. Nurs Res 1982; 31:274.

9 Fox RH. Cutaneous vasomotor control in the human head, neck and upper chest. $\mathcal{F}$ Physiol 1962;161:298.

10 Bruck $K$. Temperature regulation in the newborn infant. Biol Neonat 1961; 3:65-119.

11 Silverman WA, Fertig JW, Berger AP. The influence of thermal environment upon the survival of newly born premature infants. Pediatrics 1958; 22:876-85.

12 Glass L, Silverman WA, Sinclair JC. Effect of the thermal environment on cold resistance and growth of small
infants after the first week of life. Pediatrics 1968;41:1034infants.

13 Le-Dividich J, Noblet J. Colostrum intake and thermoregulation in the neonatal pig in relation to environmental temperature. Biol Neonate 1981;40:167-74.

14 Sinclair JC. Management of the thermal environment. In: Sinclair JC, Bracken MB, eds. Effective care of the newborn infant. Oxford: Oxford University Press, 1992: 40-56.

15 Singh M, Rao G, Malhotra AK, Deorari AK. Assessment of newborn baby's temperature by human touch: a potentially useful primary care strategy. Indian Pediatr 1992; 29:449-52. 